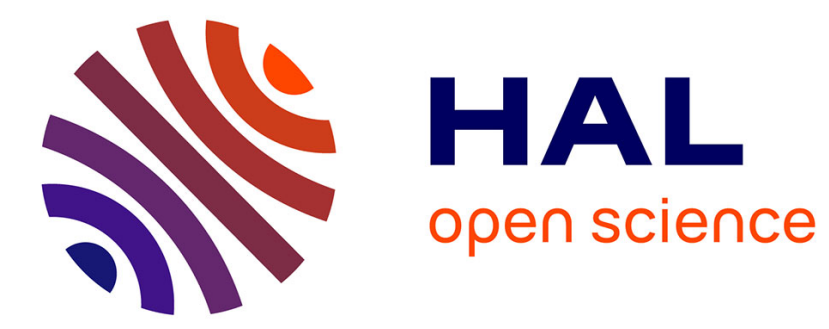

\title{
TRANSPORT PROPERTIES OF SOME SPIN GLASS SYSTEMS
}

P. W. Ford, J. Mydosh

\section{To cite this version:}

P. W. Ford, J. Mydosh. TRANSPORT PROPERTIES OF SOME SPIN GLASS SYSTEMS. Journal de Physique Colloques, 1974, 35 (C4), pp.C4-241-C4-246. 10.1051/jphyscol:1974444 . jpa-00215635

\section{HAL Id: jpa-00215635 https://hal.science/jpa-00215635}

Submitted on 1 Jan 1974

HAL is a multi-disciplinary open access archive for the deposit and dissemination of scientific research documents, whether they are published or not. The documents may come from teaching and research institutions in France or abroad, or from public or private research centers.
L'archive ouverte pluridisciplinaire HAL, est destinée au dépôt et à la diffusion de documents scientifiques de niveau recherche, publiés ou non, émanant des établissements d'enseignement et de recherche français ou étrangers, des laboratoires publics ou privés. 


\title{
TRANSPORT PROPERTIES OF SOME SPIN GLASS SYSTEMS
}

\author{
P. J. FORD (*)
}

Institute of Physics of the University, Zagreb, Yugoslavia, and

\section{J. A. MYDOSH}

Institut für Festkörperforschung, Kernforschungsanlage, Jülich, Germany

\begin{abstract}
Résumé. - On applique maintenant le terme đe verre de spin à la description de lordre magnétique et des amas dans des alliages de substitution désordonnés, avec un hôte non magnétique et de 0,5 à $10 \%$ d'impuretés magnétiques. Il semble qu'il y ait cinq combinaisons favorables d'alliages de métaux nobles avec des métaux de transition 3-d : AuFe, AuCr, AuMn, AgMn et CuMn. Le comportement résistif de ces systèmes présente un certain nombre de traits communs : un maximum bien défini à haute température, lié à la formation de paires ou triplets, c'est-à-dire d'amas, un fort terme linéaire en température près de la température d'ordre (amas gelés avec des orientations au hasard) et, à basse température, une loi en $T^{3 / 2}$, due sans doute à des excitations localisées.

Par contre, le pouvoir thermoélectrique, plus sensible aux détails des interactions entre impuretés, présente des caractéristiques différentes suivant les systèmes.
\end{abstract}

\begin{abstract}
The term spin glass is now being applied to describe the magnetic ordering and clustering of random substitutionally disordered alloys, $i$. e. a non-magnetic host with from about $\frac{1}{2}$ to 10 at. $\%$ of localized magnetic impurities. There seem to be five highly favourable, spin glasses among combinations of noble metals with 3-d transition metals : AuFe, AuCr, AuMn, AgMn and CuMn. The resistivity behaviour of these systems exhibits a number of common features: a well-defined maximum at high temperatures related to the formation of pairs, triplets, i. e. clustering, a strong linear temperature dependence near the ordering (freezing of the clusters with random alignment) temperature, and at lower temperatures a $T^{3 / 2}$ dependence probably due to localized excitations. The thermopower, by contrast, being more sensitive to the details of the interactions between impurities, shows some rather dissimilar features between the systems.
\end{abstract}

Over the last few years there has been an extensive study of the Kondo effect [1]. The original aim of this work was to understand the behaviour of isolated magnetic impurities dissolved in a nonmagnetic host. However, in the course of these investigations, it was gradually realised that, in many systems, only in the limit of extreme dilution (often well under $50 \mathrm{ppm}$ ) could the impurities be considered as really acting independently of each other. As a result of this, there have also been some studies of the way in which the behaviour of isolated impurities is modified by correlations among the impurities due to the R.K.K.Y. interaction [2].

Recently, interest has been focused on some of these alloy systems where the concentration of impurities is very much higher than before, so that the observed effects are due to a strongly interacting set of impurities. The name «spin glass » [3] has been used to describe the clustering and the complex magnetic ordering which occur in these random, substitutionally disordered, alloys. In order to simply

(*) Present address : Institut d'Electronique Fondamentale, Université Paris XI - 91405 Orsay, France. study spin glass behaviour, it would seem that an alloy system should satisfy two important requirements. Firstly, the impurities should have a high solubility in the host, (at least up to 10 at. \%), and secondly the Kondo temperature of the system should be low $\left(T_{\mathrm{K}}<1 \mathrm{~K}\right)$, so that one has « good » magnetic moments. The 3-d transition metals dissolved in gold, copper and silver have been extensively studied from the point of view of the Kondo effect [1]. Of these systems, it appears that only five of them satisfy the above two requirements. These are $\mathrm{AuFe}, \mathrm{AuCr}$, AuMn, AgMn and CuMn, and the spin glass regime occurs roughly between 0.5 and 10 at. $\%$ of impurities. Recently, we have been systematically investigating the resistivity and the thermopower of these systems in this concentration range as a means to understand the spin glass behaviour. At present we have examined AuFe, AuCr and AuMn, and have made some preliminary measurements on AgMn. It will be seen that the resistivity of all these systems shows some rather general similarities. However, the thermopower, which is very sensitive to the details of the interactions between impurities, shows striking variations between the systems. 
In presenting our data it is useful to compare the four systems with a similar concentration of impurities. In figures 1-3 we show, respectively, the impurity resistivity $\Delta \rho\left(\Delta \rho=\rho_{\text {alloy }}-\rho_{\text {host }}\right)$ versus $T$ up to $273 \mathrm{~K}$ for the four systems with concentrations of impurities around 1.5 and 8 to 11 at. $\%$, i. e. near the beginning, around the middle and towards the end of the spin glass regime. In the figure captions we have given the ordering or "freezing" temperatures, $T_{0}$, for the four systems at these concentrations. $T_{0}$ has been obtained from a. c. susceptibility measurements on the same samples by Cannella and Mydosh [4]. They find that the a. c. susceptibility has a sharp peak at the ordering temperature which is a significant feature of the spin glass regime.

Figures 1-3 show the general features of the temperature dependence of the impurity resistivity $\Delta \rho$ in the spin glass regime. In all the systems, at the lowest temperatures, the resistivity is increasing faster than $T$. (It will be shown later that it varies as $T^{3 / 2}$.) This is followed by a strong linear $T$ dependence around the ordering temperature. All four systems show a resistance maximum at higher temperatures. Deviations from Matthiessen's rule [5] may be affecting the observed features shown in figure 1, particularly for AuMn and AgMn. For the more concentrated alloys shown in figures 2 and 3 , we feel that this effect is comparatively small. Figure 1 shows that the resistance maximum is sharp and well-defined for $\mathrm{AuCr}$, but is much broader and weaker in AuMn and AgMn, and is especially so for AuFe. Figures 2 and 3 show that as the concentration is increased in all four

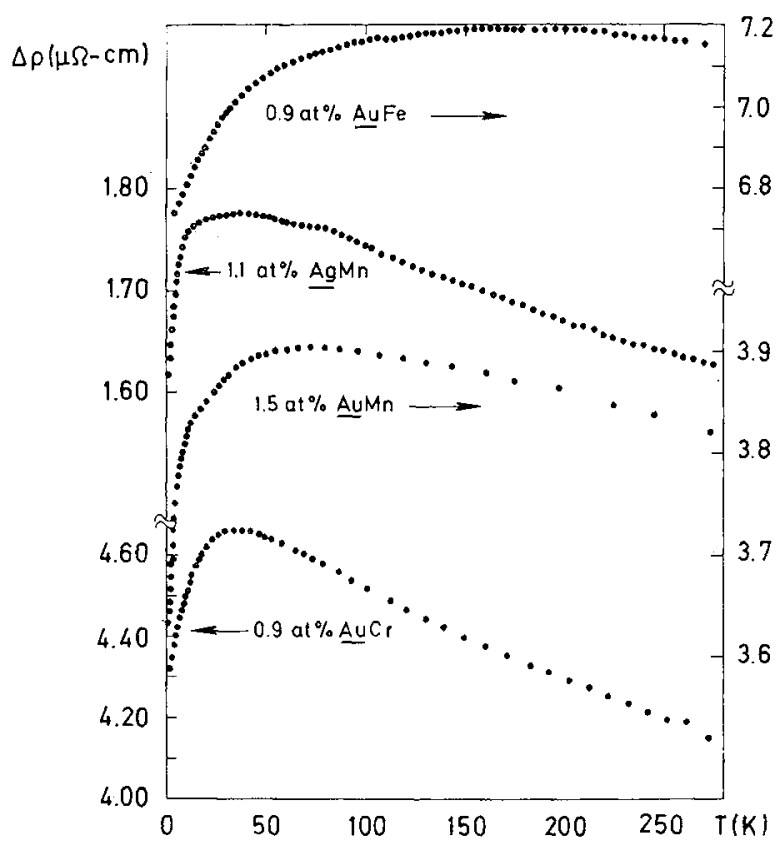

FIG. 1. - Overall temperature variation of the impurity resistivity, $\Delta \rho$, for approximately 1 at. $\%$ alloys of $\mathrm{AuCr}, \mathrm{AuMn}$, $\mathrm{AuFe}$ and $\mathrm{AgMn}$. The ordering temperatures obtained from ref. [4] for these alloys with 1 at. $\%$ concentration are respectively $15 ; 5.5 ; 8.5$ and $5.0 \mathrm{~K}$.

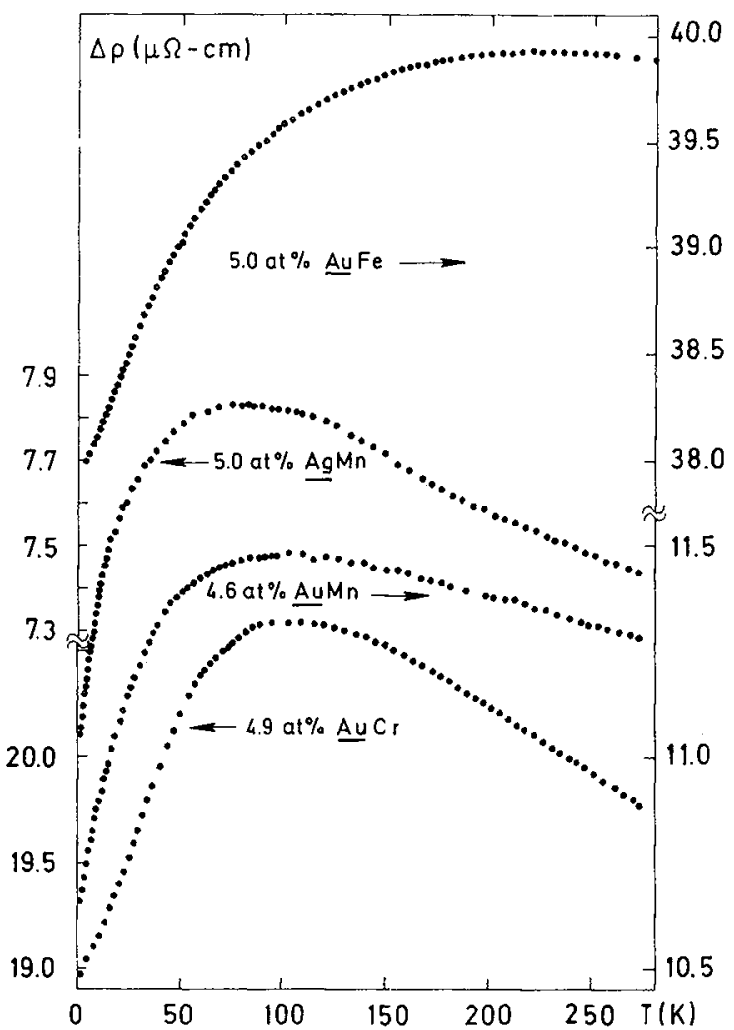

FIG. 2. - Overall temperature variation of the impurity resistivity, $\Delta \rho$, for approximately 5 at. \% alloys of $\mathrm{AuCr}, \mathrm{AuMn}$, $\mathrm{AuFe}$ and AgMn. The ordering temperatures obtained from ref. [4] for these alloys with 5 at. \% concentration are respectively $50 ; 15 ; 22$ and $19 \mathrm{~K}$.

systems the resistance maximum gets shifted to higher temperatures, and $T_{\max }$ is roughly proportional to $c^{1 / 2}$, except for $A u F e$. In addition, for all concentrations the value of $\Delta \rho_{\max }-\Delta \rho_{0}$, the residual resistivity at $T=0$, is larger in $\mathrm{AuFe}$ and $\mathrm{AuCr}$ than in both AuMn and AgMn. At $\overline{10}$ at. \% these values are approximately $4.0,3.4,2.1$ and $1.5 \mu \Omega-\mathrm{cm}$, respectively.

In discussing spin glass behaviour, one must consider the interaction energy between magnetic moments within a cluster, with a characteristic temperature $T_{\mathrm{CL}}$, and the interaction energy between clusters, with a characteristic temperature $T_{0}$, which is the ordering or «freezing» temperature. We have suggested [6] that the temperature of the resistance maximum roughly corresponds to the temperature where clusters are formed or broken up. The rather sharp resistance maximum in AuCr compared with the other systems studied, would suggest that the clusters are more easily broken up in AuCr i. e. that $T_{\mathrm{CL}}$ is particularly small. However, the larger ordering temperature $T_{0}$ in $\mathrm{AuCr}$, compared with the other systems [4], indicates that the interaction between clusters is particularly strong in this system.

The behaviour of concentrated magnetic alloys has frequently been discussed in terms of a probability distribution of internal fields [7]. This approach has been applied to the resistance maximum [8] and seems 


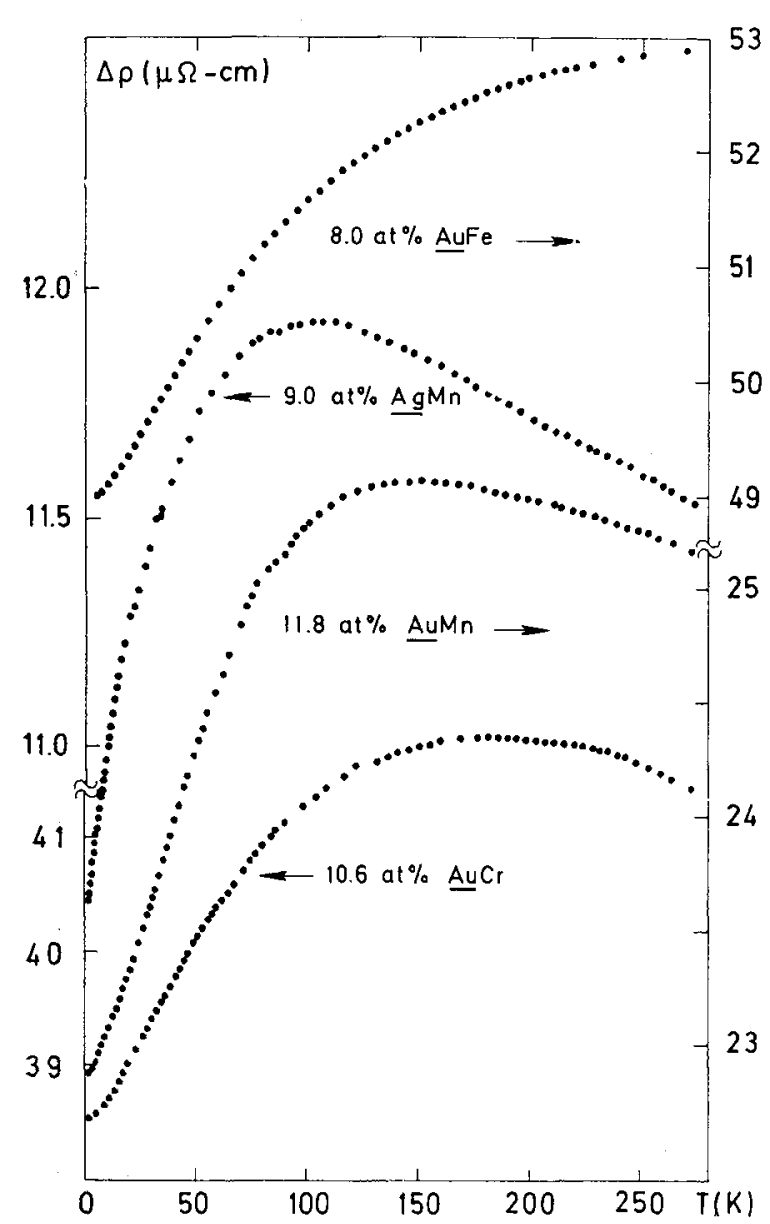

FIG. 3. - Overall temperature variation of the impurity resistivity, $\Delta \rho$, for approximately $8-11$ at. \% alloys of $\mathrm{AuCr}$, AuMn, AuFe and AgMn. The ordering temperatures obtained from ref. [4] for these alloys with 10 at. $\%$ concentration are respectively $80 ; 25 ; 32$ and $30 \mathrm{~K}$.

appropriate in understanding the resistivity behaviour above the maximum of AuFe [9] and AuMn [10] alloys up to about 0.1 at. $\%$ concentration. However, a broad distribution of internal fields does not seem to be satisfactory in the spin glass regime where there exist a low temperature $T^{3 / 2}$ dependence for the impurity resistivity, and the sharp peak for the a. c. susceptibility [11]. Likewise the pair description of the resistance maximum, due to Matho and BéalMonod [12], which was very successful in explaining the resistance maximum in several systems, becomes increasingly inadequate for concentrations above 0.1 at. \%. A very recent calculation by Jullien $e t$ al. [13] for the resistivity in nearly magnetic metals predicts a variety of resistance maxima at high temperatures which are superficially similar to some of our results for systems with «good》 moments.

We have also examined the temperature dependence of the resistivity of our alloys, down to approximately $0.5 \mathrm{~K}$. By plotting our data against various powers of $T$, we find that the temperature dependence which best fits our data is simply $T^{3 / 2}$ and in figures 4 and 5 ,

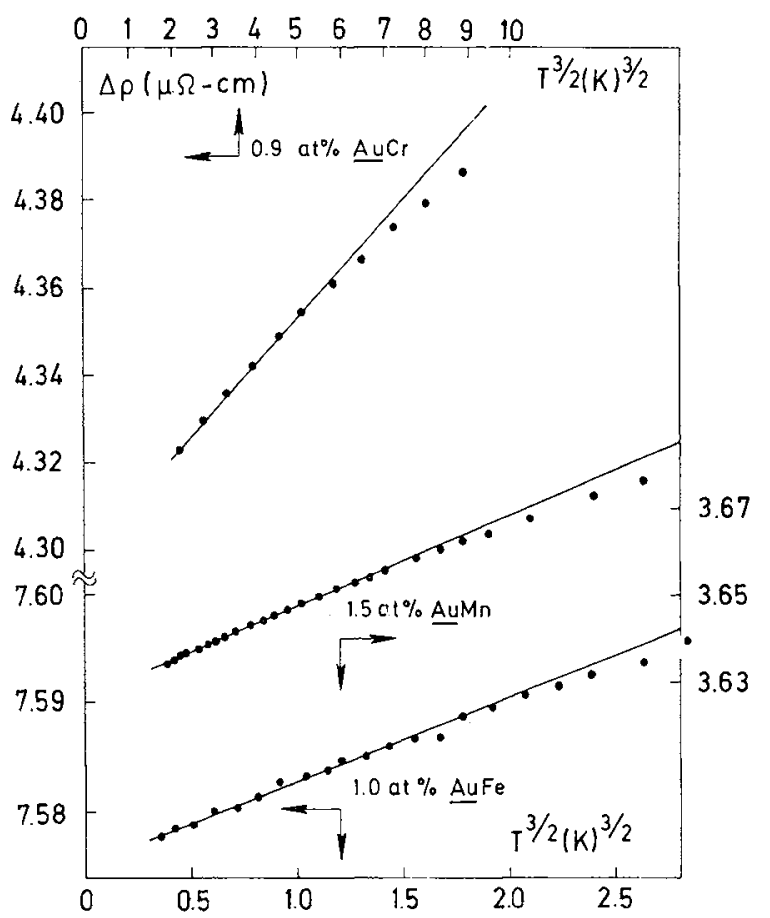

FIG. 4. - Impurity resistivity, $\Delta \rho$, plotted against $T^{3 / 2}$ for approximately 1 at. $\%$ alloys of $\mathrm{AuCr}, \mathrm{AuMn}$ and $\mathrm{AuFe}$.

we show plots of $\Delta \rho$ versus $T^{3 / 2}$ for some of our alloys. It seems that in the spin glass regime the range of this $T^{3 / 2}$ temperature dependence is much greater in $\mathrm{AuCr}$ and $\mathrm{AuFe}$ than in both $\mathrm{AuMn}$ and AgMn. $\overline{\text { We }}$ have also found that the coefficient of this $T^{3 / 2}$ term decreased very slowly with concentration. In figure 6 this coefficient is plotted against $\log c$, although a $c^{-1 / 5}$ coefficient would be equally appropriate [14]. The coefficients are approximately 15,5 , $3 \mathrm{n} \Omega-\mathrm{cm} / \mathrm{K}^{3 / 2}$ per decade of concentration, for AuMn, $\mathrm{AuCr}$ and $\mathrm{AuFe}$, respectively. Our preliminary data for AgMn further suggest a rather high value for this coefficient, and there may be a correlation between a large $T^{3 / 2}$-coefficient and a small range over which this temperature dependence occurs.

A $T^{3 / 2}$ low temperature dependence has also been observed in the dilute ferromagnetic alloys PdFe, PdMn and PdCo [15]. This behaviour has been successfully interpreted in terms of theories involving the lack of translational invariance of the electron-magnon interaction [16]. However, it is not clear how appropriate such an approach would be in describing the behaviour of a spin glass. In particular the higher temperature resistivity of a spin glass and a dilute ferromagnet are completely different, as is also the coefficient of the concentration dependence of the $T^{3 / 2}$ term. A more promising approach is probably that due to Rivier and Adkins (*), who have recently proposed a spin diffusion theory. Since a spin glass is characterized by a lack of well-defined long range

(*) Private communication. 


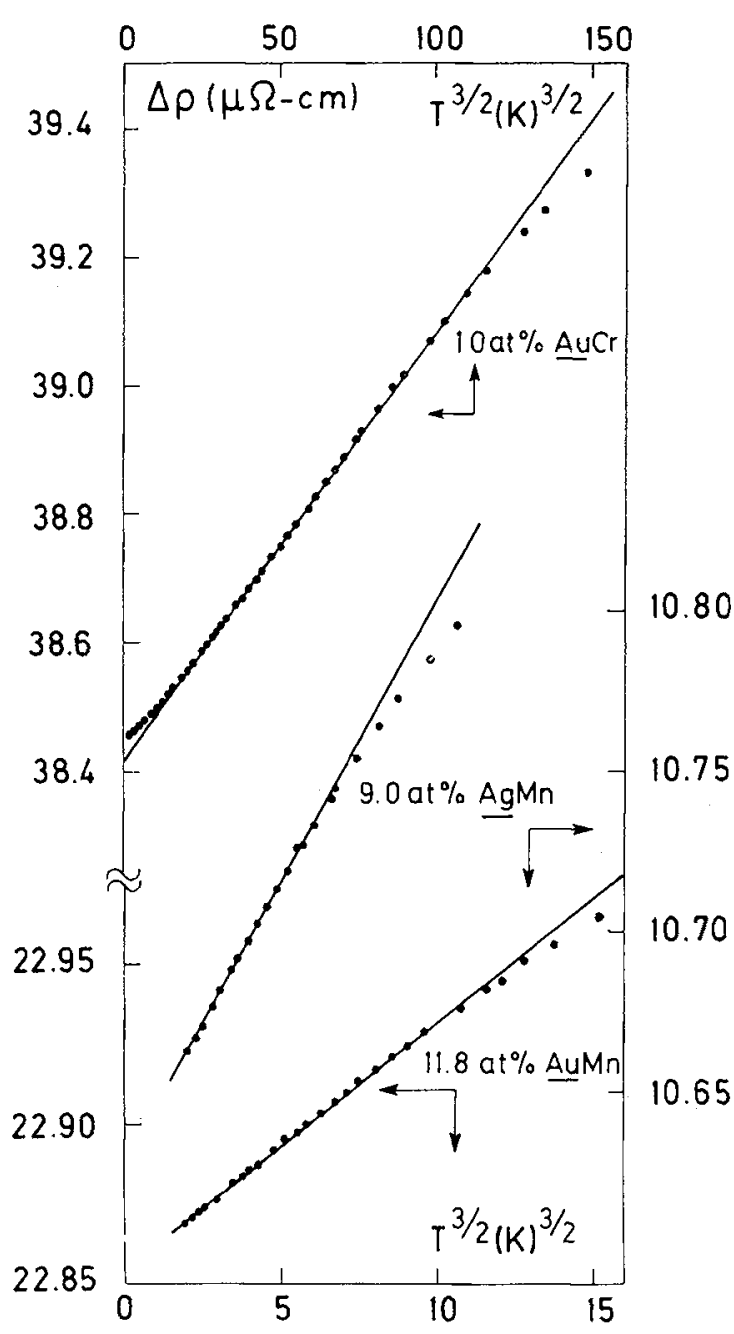

FIG. 5. - Impurity resistivity, $\Delta \rho$, plotted against $T^{3 / 2}$ for approximately 8-11 at. \% alloys of AuCr, $\underline{\mathrm{AuMn}}$ and $\mathrm{AgMn}$.

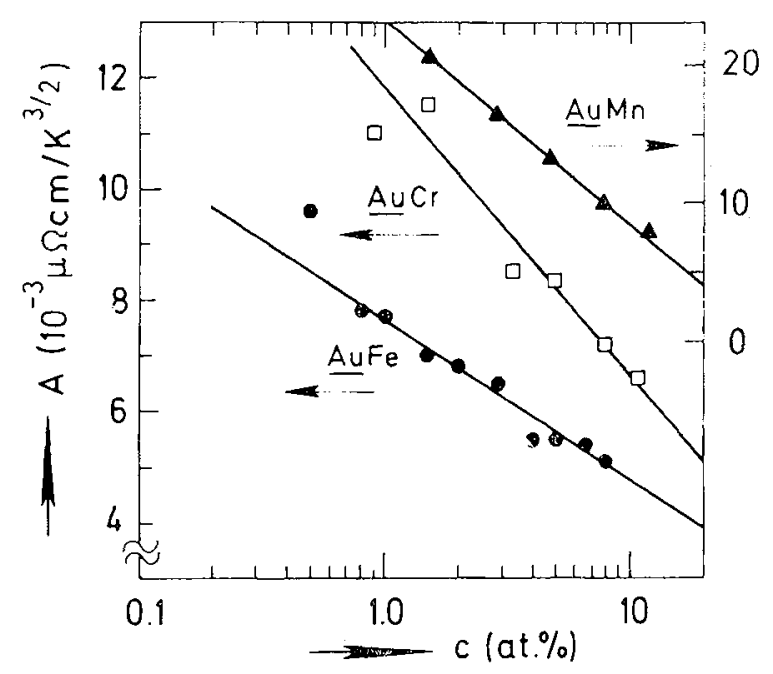

FIG. 6. - Variation, with concentration in the spin glass regime, of the coefficient of the $T^{3 / 2}$ temperature dependence for $\Delta \rho, \underline{\operatorname{AuMn}}(\boldsymbol{\Lambda}), \operatorname{AuCr}(\square)$ and $\underline{\mathrm{AuFe}}(\boldsymbol{\bullet})$. order, any spin flip excitation on an impurity site is unable to propagate like a magnon, but dies away with some diffusion constant $A$. From such a starting point, Rivier and Adkins have shown that the initial temperature dependence of the resistivity increases as $(T / \Lambda)^{3 / 2}$. However, in its present form, the theory does have difficulty in accounting for the very weak concentration dependence which we observe for the coefficient of the $T^{3 / 2}$ term.

Very recently, Laborde and Radhakrishna [17] have measured the resistivity of some $\mathrm{CuMn}$, AuFe and AuMn alloys between $30 \mathrm{~m} \mathrm{~K}$ and $\overline{4 \mathrm{~K}}$. They find that at very low temperatures (well below $0.5 \mathrm{~K}$ ), there is a $T^{2}$ temperature dependence for concentrations at the lower end of the spin glass regime. A similar transition to a $T^{2}$ dependence at low temperatures was observed in our two most concentrated $\mathrm{AuCr}$ alloys (7.9 and 10.6 at. \%). However, our measurements do show that, above $0.5 \mathrm{~K}$ for much of the spin glass regime, the low temperature resistivity of the alloy can be well represented by a $T^{3 / 2}$ law. It is very difficult from the data alone to distinguish whether this $T^{3 / 2}$ dependence is of physical significance, or only a slow transition between a $T^{2}$ and a $T$ dependence. Alternatively, a more complicated dependence [18], like $a T+b T^{2}$, could probably be used to describe our measurements. Nevertheless the proposed theory of Rivier and Adkins does give a physical interpretation to the $T^{3 / 2}$ behaviour.

In figure 7 we show the temperature dependence

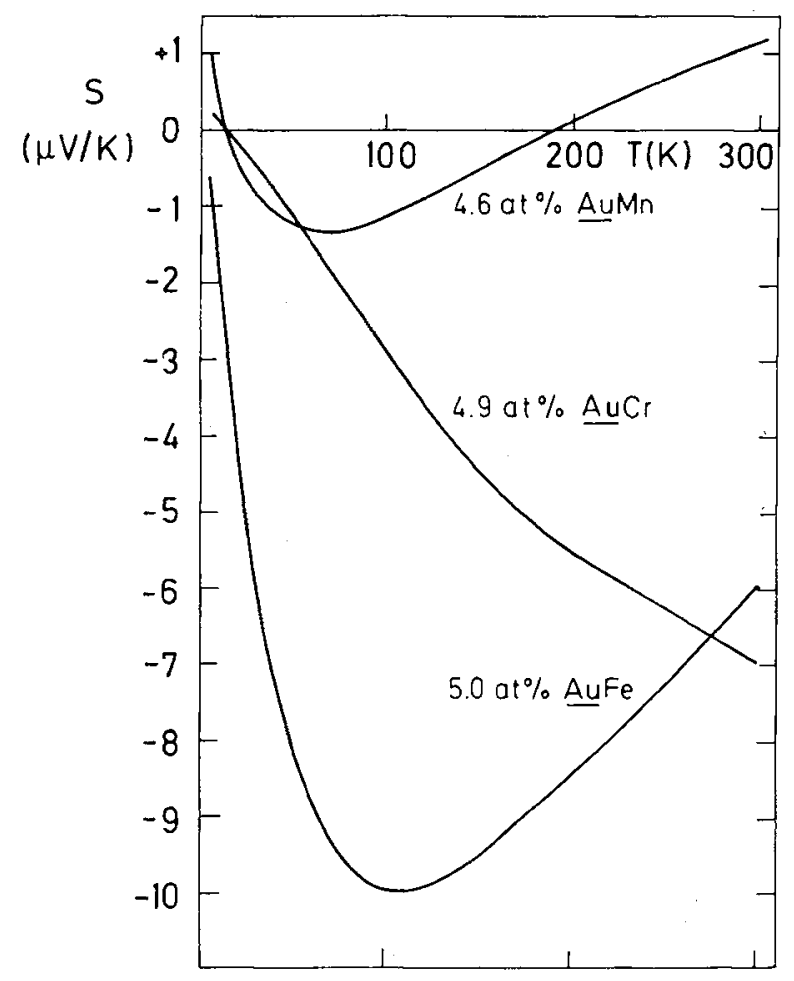

Fig. 7. - Overall temperature variation of the thermopower $S$ for approximately 5 at. $\%$ alloys of $\mathrm{AuCr}, \mathrm{AuMn}$ and AuFe. 
up to $300 \mathrm{~K}$ of the thermopower, $S$, for approximately 5 at. $\%$ alloys of AuFe, AuCr and AuMn. In a recent communication [19], we have pointed out that, although the resistivity $[6,20]$ and the susceptibility [4] of $\mathrm{AuFe}$ and $\mathrm{AuCr}$ are in many respects similar, the thermopower is strikingly different. The AuFe system has a large well-defined negative peak, and always remains negative to very low temperatures. By contrast, the thermopower of $\mathrm{AuCr}$ is much smaller and shows no indication of a peak up to at least $500 \mathrm{~K}$. At low temperatures, around $10 \mathrm{~K}$, the thermopower changes sign from being negative to positive. AuMn has features of both AuFe and $\mathrm{AuCr}$ in that it has a welldefined negative peak but also changes sign at low temperatures. The negative thermopower in AuMn is substantially smaller than in both $\mathrm{AuFe}$ and $\overrightarrow{\mathrm{AuCr}}$.

The change in the sign of the thermopower at low temperatures in AuMn and $\mathrm{AuCr}$ has previously been observed by $\overrightarrow{M a c D o n a l d}$ et al. [21] and has also been seen in AgMn [22] and $\mathrm{CuMn}$ [23] but not in $\mathrm{AuFe}[4,21], \mathrm{CuFe}[23], \mathrm{AuCo}[21]$ and $\mathrm{CuCo}$ [23]. It can be qualitatively understood from a recent theory due to Matho and Béal-Monod [24], who have considered the effect on the thermopower of interactions between pairs of impurities. According to their work, there is a «resonant " contribution from those pairs which have a Zeeman splitting of the order of $k T$, due to interactions, which is of opposite sign to the high temperature or «Kondo " part. If the impurity-impurity interactions are mainly antiferromagnetic, then the resonant part becomes the domi- nant contribution to the low temperature thermopower and a change in sign is observed. Further evidence, that within a cluster the interactions between iron atoms are mainly ferromagnetic whereas in chromium they are mainly antiferromagnetic, comes from the susceptibility [4] which in $\mathrm{AuCr}$ is much smaller than in AuFe. Based upon the long range ordering which takes place in the alloys at high concentrations, we would expect a predominance of ferromagnetic couplings between $\mathrm{Fe}$ impurities and antiferromagnetic between $\mathrm{Cr}$ impurities. A varying type of coupling would exist for $\mathrm{Mn}$ atoms depending upon the local environment. Our resistivity measurements, which show the rather sharp resistance maximum in $\mathrm{AuCr}$ compared with $\mathrm{AuFe}$, also suggest that the antiferromagnetic clusters are more easily broken up than the ferromagnetic clusters.

Although we have suggested some tentative explanations of our results, our understanding of the spin glass regime is still insufficient to provide any detailed explanation of these measurements. However it is hoped that our systematic study of the transport properties of spin glasses will stimulate additional theoretical activity in this area and provide a deeper understanding of this concentration regime.

We have benefitted from useful discussions with Dr. J. R. Cooper of Zagreb University, and Dr. N. Rivier and other members of the metal physics group of Imperial College, London. Experimental assistance from several members of the Institute of Physics, Zagreb University, is acknowledged.

\section{References}

[1] See for example the review article by HeEger, A. J., in Solid State Physics, edited by F. Seitz, D. Turnbull and H. Ehrenreich (Academic Press, New York) 1969, 23, 238, and J. Kondo, ibid. p. 181. Also the review article by Rizzuto, C., Adv. Phys. 1973, to appear.

[2] See for example Souletie, J. and Tournier, R., J. Low Temp. Phys. 1 (1969) 95.

[3] Spin glass behaviour has been discussed in various papers in Amorphous Magnetism edited by H. O. Hooper and A. M. de Graaf. (Plenum Press, New York) 1973. An alternative name of "mictomagnet" due to Beck (BeCK, P. A., Met. Trans. 2 (1971) 2015; J. Less. Common Metals 28 (1972) 193), is now being used for. more concentrated alloys where there are giant clusters and moments.

[4] Cannella, V., ref. [3], p. 195. Also Cannella, V. and Mydosh, J. A., Phys. Rev. B 6 (1972) 4420 ; International Conference on Magnetism, Moscow (1973) (to appear), and in Magnetism and Magnetic Materials, 1972 A. I. P. Conference Proceedings No 10, edited by C. D. Graham, Jr. and J. J. Rhyne (American Institute of Physics, New York) 1973, p. 785.

[5] Whall, T. E., Ford, P. J. and Loram, J. W., Phys. Rev. B 6 (1972) 3501.
[6] MYdosh, J. A. and Ford, P. J., ref. [3], p. 237 (1973): Proceedings of the International Conference on Magnetism, Moscow 1973, to appear.

[7] See for example KLeIN, M. W. and Brout, R., Phys. Rev. 132 (1963) 2412, and

Marshall, W., Phys. Rev. 118 (1960) 1519 and more recently,

RIVIER, N. and ADKins, K., ref. [3], p. 215 and ANDERson, P. W., ref. [3], p. 1.

[8] Silverstein, S. D., Phys. Rev. Lett. 16 (1966) 466, and Harrison, R. J. and KleIn, M. W., Phys. Rev. 154 (1967) 540.

[9] Ford, P. J., Whall, T. E. and Loram, J. W., Phys. Rev. B 2 (1970) 1547.

[10] Loram, J. W., Whalk, T. E. and Ford, P. J., Phys. Rev. B 3 (1971) 953.

[11] See the discussion section in the paper by CANnella, V., ref. [3], p. 205.

[12] Matho, K. and Béal-Monod, M. T., Phys. Rev. B 5 (1972) 1899.

[13] Jullien, R., Béal-Monod, M. T. and Coqblin, B., Phys. Rev. Lett. 30 (1973) 1057. 
[14] We would like to thank Dr. N. Rivier for pointing out this concentration dependence to us.

[15] Williams; G., J. Phys, \& Chem. Solids 31 (1970) 529; Wiruiams, G. and Loram, J. W., J. Phys. \& Chem. Solids 30 (1969) 1827 and Solid State Commun. 7 (1970) 1262.

[16] Long, P. D. and Turner, R. E., J. Phys. C 2 (1970) S 127 and Mills, D. L,, FerT, A. and CAMpbell, I. A., Phys. Rev. B 4 (1971) 196.

[17] Laborde, O. and Radhakrishna, P., J. Phys. F 3 (1973) 1731 and Proceedings of the International Conference on Magnetism, Moscow (1973) (to appear).

[18] Gautier, F. and Loegel, B., Solid State Commun. 11 (1972) 1205.
[19] Ford, P. J., CoOper, J. R., JUnGfleisCh, N., and Mydosh, J. A., Solid State Commun. 13 (1973) 857.

[20] Ford, P. J., Babić, E. and Mydosh, J. A., J. Phys. F 3 (1973) L 75.

[21] MacDonald, D. K. C., Pearson, W. B. and Templeton, I. M., Proc. R. Soc. London ser. A 266 (1962) 161.

[22] Malm, H. L. and Woods, S. B., Can. J. Phys. 44 (1966) 2293.

[23] Kuekshus, A. and Pearson, W. B., Can. J. Phys. 40 (1962) 98.

[24] Matho, K. and BÉal-Monod, M. T., Proceedings 13th International Conference on Low Temperature Physics (to appear) and to be published. 